\title{
Author Correction: A disinhibitory mechanism biases Drosophila innate light preference
}

\author{
Weiqiao Zhao ${ }^{1,2}$, Peipei Zhou ${ }^{2}$, Caixia Gong ${ }^{2}$, Zhenhuan Ouyang ${ }^{3}$, Jie Wang ${ }^{1,2}$, \\ Nenggan Zheng ${ }^{3} \&$ Zhefeng Gong ${ }^{1,2}$
}

Correction to: Nature Communications https://doi.org/10.1038/s41467-018-07929-w; published online 10 January 2019.

The original version of this Article contained an error in the author affiliations.

Affiliation 2 incorrectly read 'Department of Neurology of the Second Affiliated Hospital, Department of Neurobiology, Key Laboratory of Medical Neurobiology of the Ministry of Health of China, Key Laboratory of Neurobiology, Zhejiang University School of Medicine, Hangzhou, Zhejiang 310007, China' and affiliation 3 incorrectly read 'Qiushi Academy for Advanced Studies, Zhejiang University, Hangzhou, Zhejiang 310058, China.

This has now been corrected in both the PDF and HTML versions of the Article.

Published online: 29 January 2019

\begin{abstract}
(c) (i) Open Access This article is licensed under a Creative Commons Attribution 4.0 International License, which permits use, sharing, adaptation, distribution and reproduction in any medium or format, as long as you give appropriate credit to the original author(s) and the source, provide a link to the Creative Commons license, and indicate if changes were made. The images or other third party material in this article are included in the article's Creative Commons license, unless indicated otherwise in a credit line to the material. If material is not included in the article's Creative Commons license and your intended use is not permitted by statutory regulation or exceeds the permitted use, you will need to obtain permission directly from the copyright holder. To view a copy of this license, visit http://creativecommons.org/licenses/by/4.0/.
\end{abstract}

(C) The Author(s) 2019

\footnotetext{
${ }^{1}$ Department of Neurology of the Second Affiliated Hospital, Zhejiang University School of Medicine, Hangzhou, Zhejiang 310058, China. ${ }^{2}$ Department of Neurobiology, Key Laboratory of Medical Neurobiology of the Ministry of Health of China, Key Laboratory of Neurobiology, Zhejiang University School of Medicine, Hangzhou, Zhejiang 310058, China. ${ }^{3}$ Qiushi Academy for Advanced Studies, Zhejiang University, Hangzhou, Zhejiang 310007, China.

Correspondence and requests for materials should be addressed to N.Z. (email: zng@zju.edu.cn) or to Z.G. (email: zfgong@zju.edu.cn)
} 